\title{
総頸動脈閉塞症に対する外科的治療
}

\author{
二階堂 雄次, 湯 浅 隆 史, 黒川 紳一郎, 橋 本 浩 \\ 青木 秀夫, 宮本 和 典, 大西 英之*
}

\section{Surgical Treatment of Common Carotid Artery Occlusion}

Yuji Nikaido, M.D., Takashi Yuasa, M.D., Shinichiro Kurokawa, M.D.

Hiroshi Hashimoto, M.D., Hideo Aoki, M.D., Kazunori Miyamoto, M.D., and Hideyuki OHNishi, M.D.*

Department of Neurosurgery, Osaka-Minami National Hospital, and

*Department of Neurosurgery, Osaka Neurological Institute, Osaka, Japan

Summary : The clinical features of common carotid artery occlusion and principles of its adequate treatment were assessed by analyzing the disease in 7 cases who underwent reconstructive surgery between 1980 and 1985. The occlusions were unilateral in 4 cases and bilateral in 3 cases, and the causes were arteriosclerosis in 2 cases, arteritis in 1 case and aortitis syndrome in 4 cases. The modes of onset were TIA-RIND in 4 cases and minor stroke in 3 cases. Concerning the hemodynamics, the patency of the internal carotid artery via collateral circulation was observed in 8 blood vessels out of a total of 10 occluded blood vessels, and the external carotid artery was patent in 2 cases in whom occlusion extended to the internal carotid artery. The cases of aortitis syndrome were complicated by multiple large vessel occlusions. Operations were performed according to the hemodynamics. These were 9 grafts ( 8 vein grafts and 1 artificial blood vessel) and 2 transpositions: subclavian-internal carotid artery bypass in 1 case, subclavian-external carotid artery bypass plus STAMCA bypass in 2 cases, subclavian-common carotid artery bypass in 2 cases and bilateral aortaecommon carotid artery bypass in 1 case.

Patency of the bypass was obtained in all the cases. A reoperation was required in 1 case as stenosis of the vein graft occurred in 1.7 years. The therapeutic results were 'good recovery' in 4 cases and 'moderately disabled' in 3 cases, and the symptoms resulting in 'moderately disabled' were caused by neurological deficits that existed preoperatively. Improvements were attained of the symptoms due to low perfusions such as amaurosis fugax and orthostatic dizziness. Selection of the operative mode for common carotid artery occlusion should be made according to the hemodynamics by collateral circulation and occlusive lesion complicated, and operative indications were found as subclavian-common carotid artery bypass in the cases of patent common carotid artery, subclavian-internal carotid artery bypass in the cases of patent internal carotid artery and subclavianexternal carotid artery bypass plus STA-MCA bypass in the case of patent external carotid artery. Multiple graftings should be made by exposing the aortic arch in aortitis syndrome associated with multiple large blood vessel occlusion.
Key words :

- common carotid artery

- bypass surgery

- vein graft 


\section{はじめに}

頸部内頸動脈狭窄症 - 閉塞症に対する外科的治療として の血栓内膜剥離術や EC-IC バイパス術は, その手術適応 例に対しての治療手技としては確立されているといえる. それに対して総頸動脈閉塞症に関しては, その頻度は少な くまた血行動態は一様でないため選択されるべき外科的治 療として確立されたものはない. 本報告の目的は, 自験 7 例における総頸動脈閉塞症の臨床的検討から, 本疾患に対 する外科的治療の選択について検討することである.

\section{対 象 (Table 1)}

対象は1980年から1985年までに血行再建術を施行し 5 年 以上の追跡が可能であった総頸動脈完全閉塞症 7 例 (男性 2 例, 女性 5 例, 年齢 22 63歳, 平均 41歳)である. 閉塞 の原因は動脈硬化性 2 例, 血管炎 1 例, 大動脈炎症候群 4 例で, 発症様式は TIA・RIND 4 例, minor stroke 3 例 であった。

血管撮影所見を Fig. 1 にまとめた。総頸動脈閉塞が一 側性のもの 4 例, 両側性のもの 3 例で, いずれの例でも総 頸動脈以外の部位に閉塞性病変の合併がみられた。側副血 行を介する内頸動脈開存が計 10 閉塞血管中 8 血管に認めら
れ，外頸動脈は全例で開存していた。

術式の選択は, 側副血行を介しての遠位総頸動脈, 内頸 動脈，外頸動脈の開存の有無，および合併する大血管閉塞 性病変の程度によって決定され，9 graft（vein graft 8, 人工血管 1 ), 2 transposition の計 11 の再建術が施行され た。その内訳は，鎖骨下-内頸動脈バイパス 1 例，鎖骨下外頸動脈バイパス＋STA-MCA バイパス 2 例, 鎖骨下-総 頸動脈バイパス 2 例, 両側での大動脈-総頸動脈バイパス 1 例であった(Fig. 1)。なお，1例 (Case 6)では手術に先 立って左鎖骨下動脈狭窄に対し percutaneous transluminal angioplasty が施行された.

\section{症 例 呈 示}

\section{$<$ Case 3 $>$ 59歳, 男性.}

1 力月前より右一過性黒内障が頻回にあり左片麻疩も一 過性に伴うようになったため当科を受診した，入院時神経 学的に異常はみられなかったが, 入院後抗血栓療法にもか かわらず 4 回の TIA (左片麻痺・黑内症)を繰り返した. 血管写では, 右総頸動脈が分岐後 $2 \mathrm{~cm}$ の所で完全に閉塞 し, 外頸動脈は右椎骨動脈からの側副血行を介して造影さ れたが内頸動脈は造影されなかった(Fig. 2A). 手術は 2 期的に行った。まず大伏在静脈を用いた右鎖骨下動脈一外

Table 1 Cases of common carotid artery occlusion

\begin{tabular}{|c|c|c|c|c|c|c|}
\hline Case & Age $\cdot$ Sex & Cause & Symptom & Angiography & Operation & Outcome \\
\hline 1 & $34, \mathrm{M}$ & arteritis & $\begin{array}{l}\text { TIA } \\
\text { (hemiparesis) }\end{array}$ & $\begin{array}{l}\text { Lt. CC occlusion } \\
\text { Rt. CC stenosis }\end{array}$ & $\begin{array}{l}\text { Lt. SA-EC graft } \\
\text { Lt. ST-MC bypass }\end{array}$ & GR \\
\hline 2 & $52, \mathrm{~F}$ & arteriosclerosis & $\begin{array}{l}\text { RIND } \\
\text { (aphasia) }\end{array}$ & $\begin{array}{l}\text { Lt. CC occlusion } \\
\text { Rt. IC stenosis }(40 \%) \\
\text { Rt. VA stenosis }(50 \%)\end{array}$ & $\begin{array}{l}\text { Lt. SA-IC graft } \\
\text { (Rt. CEA) }\end{array}$ & GR \\
\hline 3 & $59, \mathrm{M}$ & arteriosclerosis & $\begin{array}{l}\text { TIA } \\
{\left[\begin{array}{l}\text { hemiparesis } \\
\text { amaurosis }\end{array}\right]}\end{array}$ & Rt. CC occlusion & $\begin{array}{l}\text { Rt. SA-EC graft } \\
\text { Rt. ST-MC bypass }\end{array}$ & GR \\
\hline 4 & $30, \mathrm{~F}$ & aortitis syndrome & $\begin{array}{l}\text { minor stroke } \\
{\left[\begin{array}{l}\text { hemiparesis } \\
\text { aphasia }\end{array}\right]}\end{array}$ & $\begin{array}{l}\text { Lt. CC occlusion } \\
\text { Rt. IN occlusion } \\
\text { Lt. SA stenosis }(60 \%) \\
\text { Lt. MC occlusion }\end{array}$ & $\begin{array}{l}\text { Aorta-Rt. CC graft } \\
\text { Aorta-Rt. SC graft }\end{array}$ & $\begin{array}{c}\text { MD } \\
\text { improve }\end{array}$ \\
\hline 5 & $39, \mathrm{~F}$ & aortitis syndrome & $\begin{array}{l}\text { TIA } \\
\text { (hypesthesia) }\end{array}$ & Bil. CC occlusion & Rt. SA-CC graft & GR \\
\hline 6 & $39, \mathrm{~F}$ & aortitis syndrome & $\begin{array}{l}\text { minor stroke } \\
\text { (hemiparesis) }\end{array}$ & $\begin{array}{l}\text { Bil. CC occlusion } \\
\text { Lt. SA stenosis }(70 \%) \\
\text { Rt. IN stenosis }(50 \%)\end{array}$ & Lt. SA-CC graft & $\begin{array}{c}\text { MD } \\
\text { improve }\end{array}$ \\
\hline 7 & $22, \mathrm{~F}$ & aortitis syndrome & $\begin{array}{l}\text { minor stroke } \\
{\left[\begin{array}{l}\text { hemiparesis } \\
\text { aphasia }\end{array}\right]}\end{array}$ & $\begin{array}{l}\text { Rt. CC occlusion } \\
\text { Rt. IN occlusion } \\
\text { Lt. CC occlusion } \\
\text { Lt. SA occlusion }\end{array}$ & Aorta-Bil CC graft & $\begin{array}{c}\text { MD } \\
\text { improve }\end{array}$ \\
\hline
\end{tabular}

CC; common carotid IC; internal carotid IN; innominate SA; subclavian $\mathrm{MC}$; middle cerebral

EC; external carotid ST; superficial temporal

GR; good recovery $\mathrm{MD}$; moderately disabled 


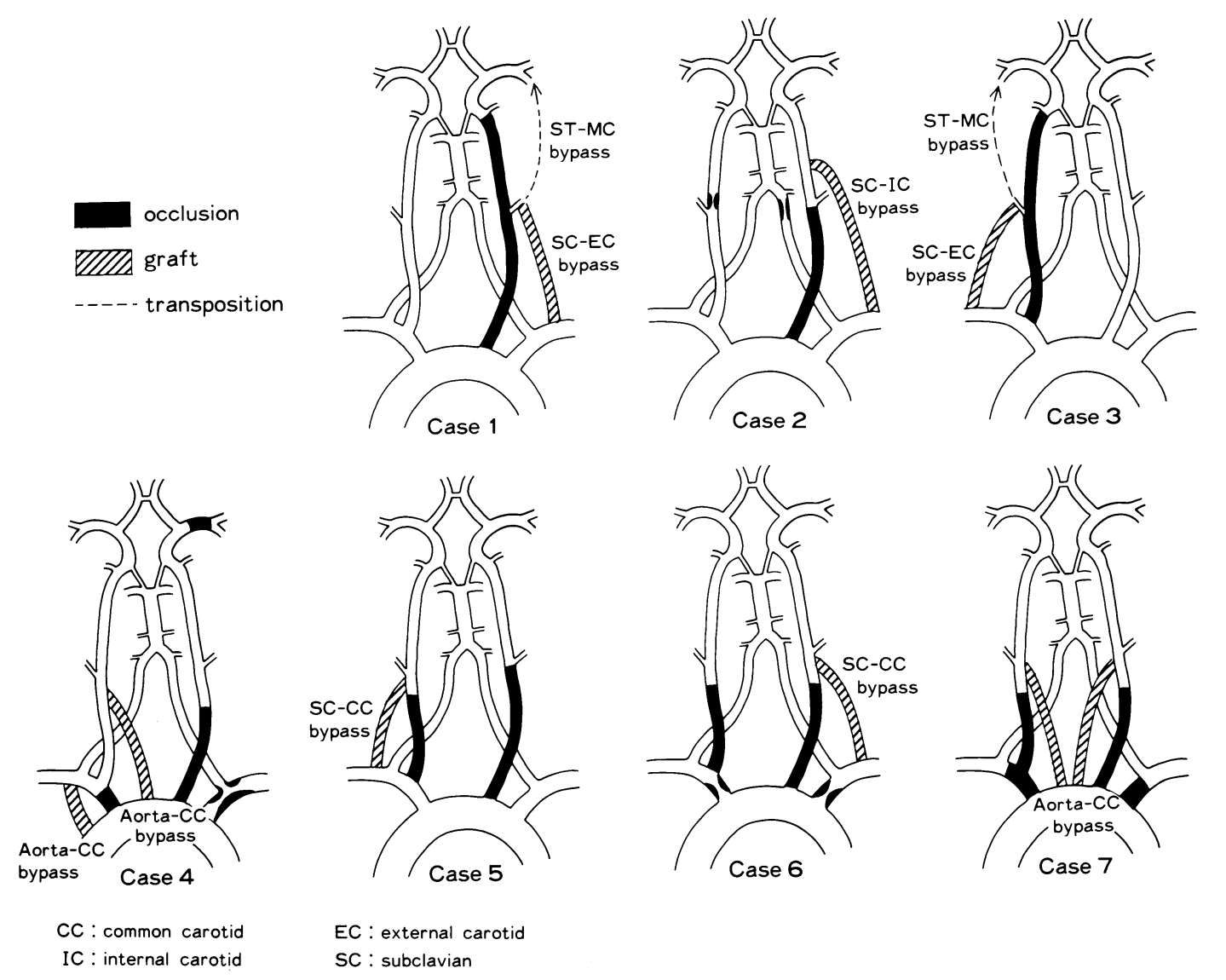

Fig. 1 Schematic representation of angiographical findings and surgical procedures.

頸動脈バイパス術を行い(Fig. 2B)，2 週間後 STA-MCA バイパス術を施行した(Fig. 2C,D)。術後経過は良好で, 3 年後の現在まで 1 度の脳血管発作も認めていない。

$\langle$ Case 7> 22 歳, 女性.

突然の意識消失発作とそれに続く右片麻痺 $(3 / 5)$, 運動 性失語症で発症. 入院後も失神, 霧視の発作を反復した。 血管撮影では腕頭動脈, 左総頸動脈, 左鎖骨下動脈の閉塞 が認められ，側副血行を介して，右側では鎖骨下・椎骨動 脈および遠位総頸動脈が, 左側では遠位総頸動脈, 椎骨動 脈が血流遅延を伴いつつも造影された(Fig. 3A). 本例に 対しては, 大動脈弓より両側の総頸動脈に $8 \mathrm{~mm}$ 径 Dacron graftを用いて 2 本のバイパスを作製した(Fig. 3B). 電磁血流計を用いた測定では, 右 $370 \mathrm{ml}$, 左 $380 \mathrm{~m} l$ のバ イパス内血流が得られた。術後，脳灌流圧低下によると思 われる失神発作などの症状の改善を認め, 右片麻痺も $4 / 5$ に改善し退院した。

\section{結 果 (Table 1)}

全例でバイパスの開存が確認された。ただし 1 例 (Case 5)では 1.7 年後に vein graft 狭窄をきたし再手術を要した.
その際の手術所見はバイパス近位部で fibrous bandによ る圧迫所見があり, 狭窄部の摘出・静脈片の再吻合で血行 再健を行った.

手術合併症はなく, 治療成績は good recovery 4 例, moderately disabled (MD) 3 例であった. MD 例は術前か らの神経脱落症状によるもので amaurosis fugax や orthostatic dizziness などの low perfusionによると思われる症 状の改善は得られた.

\section{考察}

動脈硬化に起因する閉塞性脳血管障害のうち総頸動脈閉 塞症の頻度は 4 - 5\%と報告されているが(1)3)5), 本邦に 多い大動脈炎症候群ではしばしば認められる所見であり, 血管外科領域においてはそれほどまれな疾患ではないもの と推定される.

総頸動脈閉塞症の手術適応に関しては, 動脈硬化性の場 合は, 高齢でないこと, 発作型が major completed stroke でないこと, 内科的治療で発作が反復するかもしくは側副 血行が十分に発達していないこと, 他に重篤な合併症を有 していないこと, が挙げられる。一方, 大動脈炎症候群で は病変自体が進行性であるという特徵があり, 脳虚血症状 


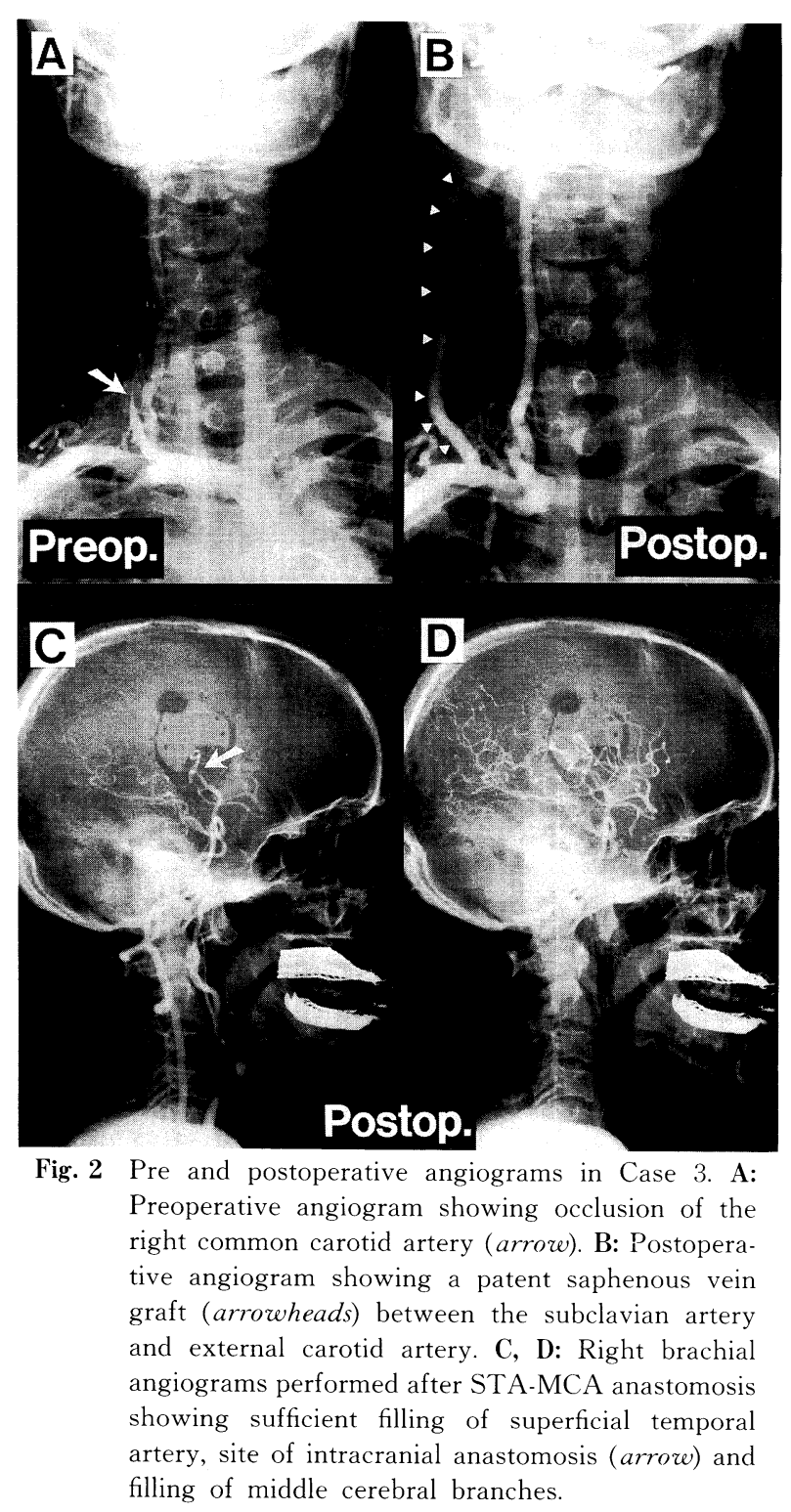

が存在しかつ両側総頸動脈が閉塞している例での予後は不 良であるためなんらかの血行再建が必要とされている ${ }^{11)}$. ただし，本シリーズは私どもの施設に局所脳血流測定装置 が導入される以前の症例であり局所脳血流に関する検索が なされていないが，今後は上記の臨床的および神経放射線 的検討に加え局所脳血流動態からの検討もなされるべきで あろう。

総顓動脈完全閉塞症に対する血行再建法としては，血栓 内膜剝離術，鎖骨下動脈一内頸動脈バイパス術，鎖骨下動 脈一外頸動脈バイパス術+STA-MCA バイパス術，鎖骨下 動脈一中大脳動脈バイパス術, 大動脈-総頸動脈バイパス術 などが報告されている(1)4)577)8)9112)。術式の選択は，閉塞 の部位，拡がり，側副血行による血行動態，合併寸る閉塞 病変などに応じて決定すべきであるが, 総頸動脈閉塞症で

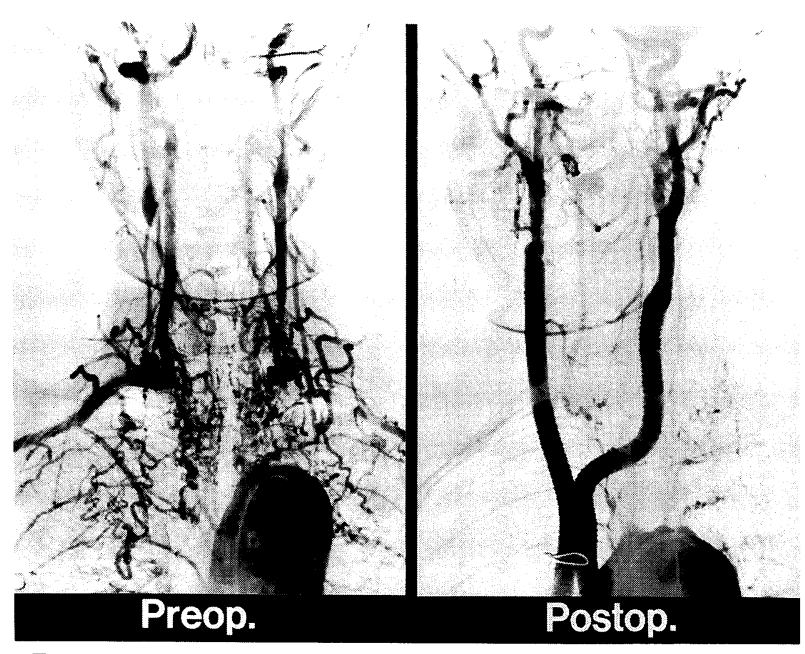

Fig. 3 Pre and postoperative angiograms in Case 7. Left: Preoperative aortogram showing occlusion of the brachiocephalic, bilateral common carotid and left subclavian arteries. Right: Postoperative aortogram showing the bilateral common carotid arteries reconstruction with two Dacron grafts.

は，閉塞部より末梢の側副血行の情報が血管撮影では必ず しも十分に把握できないという点に注意を要する．報告例 を検討すると，外頸動脈はまず $100 \%$ 開存しているが7 12), 同側内頸動脈の開存に関しては, $11.1 \%{ }^{1)}$ から $72.7 \%{ }^{12)}$

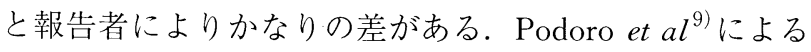
と, 9 例中術前の脳血管写で同側内頸動脈の関存が確認で きたのは 2 例のみで，残る 7 例の手術所見では 4 例が実際 には開存していたと記載している. percutaneous Doppler ${ }^{6)}$, periorbital Doppler ${ }^{9)}$, MRI ${ }^{4)}$, rapid sequence dynamic $\mathrm{CT}^{6)}$ などにより非侵襲的に内頸動脈開存の有無を知 る試みも報告されているが fault negative の可能性は否定 できず，現時点では診査手術による確認が最も確実な方法 と思われる.すなわち, 内頸動脈が閉塞していると思われ る症例に対しては，鎖骨下動脈-中大脳動脈バイパスと鎖 骨下動脈一外頸動脈バイパス+ STA-MCA バイパスの 2 法 が考えられるが，上記の理由でまずは頸部にアプローチし 内頸動脈が開存していれば鎖骨下動脈一内頸動脈バイパス を行い，閉塞していれば鎖骨下動脈一外頸動脈バイパスを 施行した後 STA-MCA バイパスを追加すべきと考える.

Diaz et $a l^{2)}$ は short vein graft の開存率が 100\%であった のに対し long graft である鎖骨下動脈-中大脳動脈バイパ スの開存率は $58 \%$ と不良であったと報告しており，この 点からも上記の方針は容認されるべきものと考える.

著者らの術式選択に関する考えをまとめると, 遠位総頸 動脈開存例では鎖骨下-総頸動脈バイパス, 内頸動脈開存 例では鎖骨下一内頸動脈バイパス，外頸動脈開存例では鎖 骨下一外頸動脈バイパス＋STA-MCA バイパスが第一選択 と考える.また, 複数の大血管閉塞を併う大動脈炎症候群 
での血行再建については通常 1 本のみを再建すれば十分と の意見があるが11), 若年の進行性疾患であることを考慮 して可能であれば multiple grafting を施行すべきと考える 8).その場合は術後の hyperemia に注意し厳重な血圧管理 が必要であるのはいうまでもない. また.グラフト材料と して，著者らは当初 saphenous vein graft を用いていたが 将来, 上行大動脈壁自体に炎症が及んで中枢端縫合部の狭 窄をきたしうるため, できるだけ径の大きいグラフト材料 を選ぶべきであり ${ }^{8)}$ ，また静脈採取の必要がないという点 で人工血管の使用が望ましいと考えている。

\section{文献}

1) Collice M, D'angelo V, Arena O: Surgical treatment of common carotid artery occlusion. Neurosurgery 12: 515524, 1983

2) Diaz FG, Pearce J, Ausmann JI: Complication of cerebral revascularization with autogenous vein graftp. Neurosurgery 17: 271-276, 1985

3) Fisher CM: Occlusion of the carotid arteries: Further experiences. Arch Neurol Psychiatry 72: 184-204, 1954

4) Heinz ER, Yeates AE, Djang WT: Significant extracranial carotid stensis: Detection on routine cerebral MR images.
Radiology 170: 843-848, 1989

5) Heros RC, Sekhar LM: Diagnostic and therapeutic alternatives in patients with symptomatic "carotid occlusion" referred for extracranial-intracranial bypass surgery. J Neurosurg 54: 790-796, 1981

6) Kawaguchi T, Fujita S, Ijichi A, et al: Successful reconstruction of completely obstructed right CCA in Takayasu's disease: Usefulness of rapid sequence scanning method-Case report-. Neurol Med Chir (Tokyo) 30: 10241028,1990

7) Moore WS, Blaisdell FW, Hall AD: Retrograde thrombectomy for chronic occlusion of the common carotid artery. Arch Surg 95: 664-673, 1967

8）中島伸之, 菊池晴彦, 栗山良紘, ほか：大動脈炎症候群の 外科治療一脳虚血性病変に対して一。厚生省特定疾患 系統 的血管病変に関する調査研究班 1984年度研究報告書, 1985, pp 249-255

9) Podore PC, Rob CH, DeWeese JA, et al: Chronic common carotid occlusion. Stroke 12: 98-100, 1981

10) 斉藤洋一, 山田和雄, 早川 徹, ほか: 総頸動脈閉塞性病 変に対する外科的治療経験. Neurol Med Chir (Tokyo) 25: 356-361, 1985

11）上野 明：血管手術のタイミング。脈管学 27: 469-474, 1987

12) Wylie EJ, Effeney DJ: Surgery of the aortic arch branches and vertebral arteries. Surg Clin North Am 59: 670-680, 1979 